\title{
Youth and Jobs in Rural Africa
}

\section{Beyond Stylized Facts}

Edited by Valerie Mueller and James Thurlow

November 2019

edited bY VALERIE MUELLER AND JAMES THURLOW

\section{Youth and Jobs} in Rural Africa

The share of working-age young people (15 to 24 years old) in Africa south of the Sahara has risen due to past declines in mortality coupled with high fertility. This "youth bulge" has created a sense of urgency, and even anxiety, among national governments and the international development community as the prospect of widespread youth unemployment in Africa, and the social instability and political unrest it could bring, looms closer. As a result, governments in Africa are under enormous pressure to create more and better jobs for the region's young and rapidly growing population.

These concerns are perhaps most pronounced in rural Africa, where most of the world's poor population lives and where agriculture remains the primary income source for most households. The conventional view is that African youth do not aspire to work in agriculture, in part because the sector is characterized by low productivity and limited growth and lacks the allure of city life. Yet prospects for finding decent, well-paying jobs in urban areas are also limited, so most youth in Africa will inevitably need to find jobs somewhere in the rural economy.

Africa's youth bulge does present a challenge, but it may also prove to be an opportunity to advance rural development. A young and better-educated workforce could lead to greater use of more sophisticated farm technologies, commercial agricultural practices, and expansion of rural nonfarm enterprises. These are crucial steps for accelerating agricultural transformation in Africa, and young men and women could be the "agents of change" that the region so badly needs. The literature and debate around youth employment in Africa is therefore one of contrasts-between apprehension on the one hand, and cautious optimism on the other.

Youth and Jobs in Rural Africa: Beyond Stylized Facts questions some of the stylized facts that underpin the prevailing narratives and policy debates about youth employment in rural Africa. Is Africa's youth bulge unprecedented? Are youth more likely to adopt modern farm technologies and practices? Are youth more likely to engage in rural nonfarm activities or migrate to urban centers? Are policymakers adequately responding to the youth employment challenge, and are rural young people themselves mobilizing and demanding policy reforms from their governments? 
To address these and other questions, the book presents a series of thematic studies (global historical context, migration, policy, and political participation) as well as country case studies (Ethiopia, Malawi, Ghana, Tanzania, and Senegal) that analyze household and firm surveys across a range of country contexts. This approach differs from many studies on youth employment in Africa, which often rely on country-level data or focus on regional trends. The detailed country focus of Youth and Jobs in Rural Africa and use of survey data better reflect the wide variations observed across and within African countries. The book's focus on rural Africa and the participation of youth in agricultural transformation also helps fill an important gap in the literature.

\section{A More Nuanced Picture}

Striking a balance between alarm and optimism about Africa's youth bulge requires a better understanding of the constraints that African youth must contend with. Youth and Jobs in Rural Africa presents a holistic picture of the challenges and opportunities facing young people in rural Africa today and what these mean for inclusive growth in the region. The thematic and country case studies illuminate and elaborate on a set of stylized facts that shape the policy dialogue around youth employment in rural Africa. Following are the key findings.

\section{Africa's demographic transition and economic trends are no worse than those of other developing regions when they experienced their youth bulges three decades ago.}

Africa's youth bulge is not unprecedented, nor is it necessarily a problem in itself. Rather, the region's key challenge will be to transform African agriculture and the rural economy in order to create better jobs for all of its working-age population, both young and old.

Using historical data, including surveys and population censuses, the book's opening chapter compares economic conditions in Africa since the early-2000s with those in other developing regions around the time of their youth bulges. Despite facing a more competitive global economy, in some aspects of development Africa's trends are no worse, and are sometimes better, than they were elsewhere.

\section{Evidence that youth are more likely to adopt improved farm technologies is mixed, and even where it exists, the effect on agricultural productivity might be small.}

Raising productivity is the first step in transforming the agriculture sector. The prevailing view is that because youth in Africa today are better educated than adults and more familiar with information technology, they will be more apt to adopt advanced farm technologies and practices, including use of improved seeds and chemical fertilizers.

Using nationally representative surveys that include information on farm input use and rural services, the book's five country case studies together show that having a younger population does not necessarily lead to greater adoption of improved farm technologies. In Ethiopia, for example, youth-headed households were less likely to act on advice from extension officers and also less likely to use improved seeds and fertilizers. In Malawi, older farmers actually used more modern inputs than younger ones. And in Ghana, it was level of education rather than age that determined whether farmers embraced new practices.

\section{Youth are more likely to engage in rural nonfarm activities, but the level of off-farm employment remains low and most youth continue to work in agriculture.}

History suggests that higher agricultural productivity and commercialization help expand the rural nonfarm economy. As agricultural transformation progresses, then, more farm households should diversify into nonfarm activities, creating new job opportunities for rural youth, especially those without access to farmland. The prevailing view is that youth, by being better educated and less inclined to work on the farm, should be well positioned to establish rural businesses and drive this stage of transformation.

The country case studies confirm that, overall, youth are in fact more likely than adults to have off-farm jobs, but the extent to which this is true varies across countries and its implications for rural transformation are unclear. In all five cases, it appears that the contributions of young people to rural transformation have so far been limited, as they are more likely than older people to have low-productivity jobs in the informal sector or run less successful nonfarm businesses.

\section{Education is important for rural nonfarm employment, but on its own is not enough to ensure success.}

A common finding across all five case studies is that people working in nonfarm jobs tend to have more years of schooling. This is often thought to be one reason why youth are more likely to work off the farm. Yet all the case studies identify factors other than education that are as or more important for participation and success in off-farm work-better access to markets, transportation systems, and electricity in Ghana; capital accumulation, work experience, and social and economic networks in Malawi; and work experience and social networks in Ethiopia.

Education is undoubtedly an asset for youth, but it does not guarantee that they will lead or benefit from the rise in the rural nonfarm economy. Investing in education is therefore necessary but insufficient. Investments in infrastructure and market development are also critical to ensure that youth (and adults) can participate in the process of agricultural transformation.

\section{Participation in the rural nonfarm economy differs for young men and women.}

The roles of young men and women in the agricultural transformation process vary from country to country. The case studies find that in Malawi and Senegal, men dominate off-farm work, are more likely than women to remain in agriculture, and are more likely to emigrate in search of work. In contrast, in Ghana female-headed rural households 
engage more often in nonfarm activities, though this relationship weakens over time.

In Tanzania, the likelihood of men and women to work in the rural nonfarm economy is roughly equal, though female-run enterprises tend to be in lower-value manufacturing rather than higher-value services and tend to be less productive and successful. It is important to note, however, that other factors, such as education, are more important than gender in explaining why some businesses are successful. One implication from this is that investing in women's education in Tanzania, and possibly elsewhere, should help close the gender gap by allowing young women to participate in and benefit more from agricultural transformation.

\section{Youth are more likely to migrate, but not always for work reasons or to urban areas.}

Agricultural transformation is initially driven by increases in agricultural productivity and then by deepening farmnonfarm linkages as farmers commercialize and rural markets become more important. The prevailing view is that, given land shortages in rural areas and higher returns on education in urban areas, youth are more likely than adults to migrate and may therefore contribute more to economic growth and structural change.

However, household panel survey data from Malawi and Tanzania show that although rural youth are indeed more likely to migrate, most migration is to other rural areas rather than to cities or towns. Furthermore, rural-rural migration is less likely to be job-related than rural-urban migration. Rural-rural moves are also higher among women and often motivated by marriage. Finally, ruralrural migration is the main driver of income diversification among youth, though it rarely involves a shift into exclusive nonagricultural employment. So while youth are more likely than adults to urbanize, the importance of this for youth and for structural change should not be overstated.

\section{Rural nonfarm job opportunities are better closer to bigger cities, but jobs in the food system may be more important closer to smaller towns.}

The Malawi and Ghana case studies highlight the importance of differentiating between urban centers of different sizes. In Malawi, better access to cities of 50,000 people or more is strongly associated with nonfarm employment, while proximity to smaller urban centers has little influence on the employment choices of youth in surrounding rural areas. In Ghana, however, smaller towns are important for promoting youth employment in rural areas.

The difference between the two countries may be that economic growth and urbanization are slower in Malawi and less of the country's rural population live in peri-urban areas. In fact, Malawi's rural population density is one of the highest in Africa. The linkages between small towns and rural areas in Malawi may therefore be weaker, or less important, than in Ghana.
Youth are only slightly more likely to protest than adults, but they are more likely to be driven by concerns about unemployment.

Historical data on local protests and household surveys from 16 African countries show that youth are more likely to protest than adults, but the gap is extremely small, suggesting that concerns about youth protest may be overblown.

Young and older people participate in protest activities almost equally. Being better educated and being poor are strong motivators for protest, regardless of age. Young people are more likely to demonstrate if they are unemployed and lack trust in political institutions. To avoid protests, African governments should prioritize creating jobs that meet young people's skills and aspirations and proving that youth employment policies and initiatives are aimed at enhancing long-term economic prospects for youth rather than simply mobilizing their short-term political support.

Youth employment is now a major policy goal, but the means of achieving it are not well-represented in current policies.

Creating more and better jobs for youth is a major policy priority for most African countries today, yet national policies often fail to include the kinds of interventions needed to promote youth employment. The chapter on policies for youth employment lays out a framework for determining whether policies adequately address key barriers in rural areas and applies it to 47 national, rural, and agricultural policies in 13 African countries. The study finds that policies tend to be strongest on labor supply issues, such as self-employment and skills development, but much weaker on labor demand issues, such as stimulating private sector off-farm job creation in the agrifood system-an area that the country case studies show to be particularly important for rural youth. National policies should therefore explicitly support informal businesses in rural and periurban areas. Moreover, governments should promote institutional channels to enable youth participation in decision-making, such as producers' organizations and youth associations.

\section{Moving Forward}

The rural population in Africa south of the Sahara is growing, and its rural economy is still underdeveloped. The pressure to create jobs in rural areas is therefore particularly acute. There is cause for optimism, however. Evidence suggests that agriculture is transforming in many African countries, albeit slowly, and that youth are often participating in this process. Further research is needed to accelerate this progress.

Insights from our case studies confirm that more detailed analysis is needed at country and subnational levels.

Country case studies are more likely to reveal the unique characteristics of national employment dynamics and structural change and provide a firmer basis for decisionmaking. More important, they can reveal major variations within countries, for example, between peri-urban 
areas outside small towns versus big cities. Studies that rely on national and cross-country data cannot provide the information needed to design policies that address the specific needs of different geographies and population groups.

More and better survey data on employment, migration, and businesses in rural areas are needed-specifically, on secondary employment and part-time work, on the economic relationships that migrant and emigrant workers have with households in their home countries or communities, and on rural firms. Household surveys are crucial for understanding workers' constraints, but many businesses in rural Africa are not household enterprises and so are not captured by household surveys. It is difficult to design policies to promote private sector development in the rural nonfarm economy without information on what makes some businesses successful and others not.

Finally, national policies should be evaluated on their contributions to achieving employment goals, including youth employment in rural areas. Current policies often fall short of addressing the constraints facing young job seekers. Although the scale of policy reforms and actions needed to address Africa's youth bulge is daunting, there is an increasing alignment of interests and incentives: African governments have made youth employment a policy priority, and African youth are demanding policies that improve their job prospects. This creates promising opportunities to enact policies that effectively address rural youth employment-policies that are grounded in local evidence rather than stylized facts.

\title{
Contents
}

1 Africa's Rural Youth in the Global Context Valerie Mueller, Gracie Rosenbach, James Thurlow, and lan Masias

\section{PART I: THEMATIC TRENDS ON YOUTH EMPLOYMENT}

2 Can Migration Be a Conduit for Transformative Youth Employment?

Valerie Mueller and Hak Lim Lee

3 Policies for Youth Employment in Sub-Saharan Africa David Schwebel, Elisenda Estruch, Peter Wobst, and Ileana Grandelis

4 Troublemakers, Bystanders, and Pathbreakers: The Political Participation of African Youth Danielle Resnick

\section{PART II: CASE STUDIES ON THE ROLE OF YOUTH EMPLOYMENT IN STRUCTURAL TRANSFORMATION}

5 Rural Youth and Employment in Ethiopia

Emily Schmidt and Firew Bekele Woldeyes
6 Change and Rigidity in Youth Employment Patterns in Malawi

Todd Benson, Alvina Erman, and Bob Baulch

7 Cities and Rural Transformation:

A Spatial Analysis of Rural Youth Livelihoods in Ghana Xinshen Diao, Peixun Fang, Eduardo Magalhaes, Stefan Pahl, and Jed Silver

8 Rural Nonfarm Enterprises in Tanzania's Economic Transformation: The Role of the Youth Xinshen Diao, Eduardo Magalhaes, and Margaret McMillan

9 Youth Mobility and Its Role in Structural Transformation in Senegal

Elisenda Estruch, Lisa Van Dijck, David Schwebel, and Josee Randriamamonjy

10 Conclusion

Valerie Mueller, Gracie Rosenbach, and James Thurlow

Valerie Mueller is an assistant professor in the School of Politics and Global Studies at Arizona State University in Tempe, AZ, USA, and a nonresident fellow at the International Food Policy Research Institute (IFPRI) in Washington, DC. James Thurlow is a senior research fellow in the Development Strategy and Governance Division of IFPRI.

This synopsis is based on the book Youth and Jobs in Rural Africa: Beyond Stylized Facts, co-published by IFPRI and Oxford University Press. Any opinions stated in this book are those of the authors and not necessarily representative of or endorsed by IFPRI.

\author{
Youth and Jobs in Rural Africa: Beyond Stylized Facts is available for free download at \\ https://doi.org/10.1093/oso/9780198848059.001.0001
}

\section{INTERNATIONAL FOOD POLICY RESEARCH INSTITUTE A world free of hunger and malnutrition}

1201 Eye St, NW, Washington, DC 20005 USA | T. +1-202-862-5600 | F. +1-202-862-5606 | Email: ifpri@cgiar.org | www.ifpri.org | www.ifpri.info DOI: https://doi.org/10.2499/9780896296855 